\title{
Novas metodologias de ensino/aprendizagem: o caso da narrativa biográfica aplicada à formação em Gestão de Recursos Humanos
}

\author{
António José Almeida \\ Escola Superior de Ciências Empresariais \\ Instituto Politécnico de Setúbal \\ antonio.almeida@esce.ips.pt
}

Maria Amélia Marques

Escola Superior de Ciências Empresariais

Instituto Politécnico de Setúbal

amelia.marques@esce.ips.pt

José Rebelo Santos

Escola Superior de Ciências Empresariais

Instituto Politécnico de Setúbal

jose.rebelo@esce.ips.pt

João Pedro Cordeiro

Escola Superior de Ciências Empresariais Instituto Politécnico de Setúbal

joao.cordeiro@esce.ips.pt

\begin{abstract}
:
A integração de novos públicos no ensino superior, de que os maiores de 23 anos são o exemplo mais paradigmático, a par da tendência para adopção de novos modelos pedagógicos, potenciados pelo designado Processo de Bolonha, têm vindo a criar condições para a implementação de novas experiências pedagógicas como forma de dar sentido ao trabalho escolar para estes novos públicos. A reabilitação epistemológica do potencial formativo da experiência (Canário, 2008) surge neste contexto como um elemento central na estruturação de novas práticas pedagógicas onde o recurso ao método biográfico surge como umas das práticas de investigação/formação com elevado potencial formativo. Partindo do pressuposto de que a aprendizagem é um processo dialéctico que integra a experiência e a teoria, a observação e a acção (Cavaco, 2002), o recurso ao método biográfico assenta na valorização do saber experiencial de cada um no seu processo de auto construção como pessoa e como profissional e na valorização dos processo não formais de aprendizagem. É neste contexto que a narrativa biográfica se pode assumir como um método pedagógico relevante para a formação de profissionais portadores de experiências concretas que auto-reflectidas podem contribuir para o desenvolvimento de competências ao transformar os estudantes em actores-investigadores (Josso, 2002). Tendo em conta os pressupostos teórico/metodológicos em que assenta a metodologia da narrativa biográfica, a presente comunicação tem por objectivo dar conta de uma experiência pedagógica realizada com estudantes finalistas da licenciatura em Gestão de Recursos Humanos baseando-se na explicitação
\end{abstract}


e análise do seu percurso profissional tendo em conta as práticas de gestão de recursos humanos experienciadas. A proposta de elaboração de uma narrativa biográfica tem por objectivo caracterizar e analisar acontecimentos charneira, contextos e práticas de gestão de recursos humanos que fazem parte do percurso profissional do estudante. A análise visa a articulação entre o percurso profissional individual e os elementos teóricos que constituem a problemática da GRH tendo em vista a realização de uma síntese curricular do curso e que se constitua num processo de aprendizagem individual capaz de sustentar o desenvolvimento de competências técnicas e sociais relevantes para a formação de um profissional de gestão de recursos humanos. O balanço da experiência pedagógica permite-nos realçar o seu potencial formativo desta metodologia pedagógica na medida em que permite aos estudantes tomar consciência do sentido das suas trajectórias profissionais e dos efeitos das práticas de gestão de recursos humanos sobre essas mesmas trajectórias. De igual modo, assume particular relevância a capacidade do estudante em reflectir sobre as suas experiências a partir de um quadro conceptual próprio a par do papel do docente orientador enquanto facilitador do processo de descoberta e de consciência de si. 